\title{
EPIDURAL FENTANYL SPEEDS THE ONSET OF SENSORY AND MOTOR BLOCKS DURING EPIDURAL ROPIVACAINE ANAESTHESIA
}

\author{
A. Mohan Rao' , A. Hari Prasad², Vankineni Kuchela Babu ${ }^{3}$ \\ ${ }^{1}$ Consultant Intensivist, Department of Critical Care, Seven Hills Hospital, Visakhapatnam. \\ ${ }^{2}$ Senior Resident, Department of Anaesthesiology, Seven Hills Hospital, Visakhapatnam. \\ ${ }^{3}$ Chief Consultant and HOD, Department of Anaesthesiology and Critical Care, Seven Hills Hospital, Visakhapatnam.
}

\begin{tabular}{l}
\hline ABSTRACT \\
BACKGROUND \\
Different adjuvants are added to local anaesthetic solutions to hasten the onset of sensory and motor block in epidural \\
anaesthesia.
\end{tabular}

\section{OBJECTIVE}

To study the effect of epidural and intravenous fentanyl on time of onset of sensory and motor blockade in epidural anaesthesia with $0.75 \%$ ropivacaine.

\section{MATERIALS AND METHODS}

After obtaining informed consent and permission from hospital scientific and ethical committee 40 patients with ASA grade I and II who are undergoing lower abdominal, anogenital, urological, gynaecological, and orthopaedic surgeries are included in this study. Patients with bleeding disorders, infections at puncture site, history of opioid dependence, allergic to study drugs, pregnant ladies, age <18 years, and morbidly obese patients are excluded from this study. Patients are randomly allocated into two groups: epidural fentanyl (EF) and intravenous fentanyl (IF) with 20 patients in each group. After the test dose, Epidural Fentanyl (EF) group receive $20 \mathrm{~mL}$ of $0.75 \%$ ropivacaine plus $100 \mu \mathrm{g}$ of fentanyl $(2 \mathrm{~mL})$ followed by IV injection of $2 \mathrm{~mL}$ of normal saline. The patient in the intravenous fentanyl (IF) group receive $20 \mathrm{~mL}$ of $0.75 \%$ ropivacaine plus $2 \mathrm{~mL}$ of normal saline followed by IV injection of $100 \mu \mathrm{g}$ fentanyl $(2 \mathrm{~mL})$. Time of onset of sensory block, time of onset of motor block, upper level of sensory block, incidence of different complication are recorded during the study. Independent samples $\mathrm{t}$ - test, Kruskal - Wallis test and one way ANOVA test were used for statistical analysis.

\section{RESULTS}

The onset time for sensory block is earlier in group EF than group IF $(10.90 \pm 2.81$ mins $<16 \pm 3.03$ mins) (mean \pm SD). The motor blockade onset time is more rapid in group EF than group IF $(14.95 \pm 5.43$ mins $<26.40 \pm 5.94 \mathrm{mins})$ (mean \pm SD). The upper level of sensory block is indifferent in both groups $(1.70 \pm 0.571=1.75 \pm 0.716)$ (mean \pm SD). The incidence of different complications is insignificant in both groups ( $\mathrm{p}-0.135>0.05)$.

\section{CONCLUSION}

Epidural administration of the mixture of fentanyl and ropivacaine solution accelerated the onset of sensory and motor blocks during epidural ropivacaine anaesthesia without significant fentanyl related side effects. Fentanyl is a useful adjunct to local anaesthetic ropivacaine for epidural anaesthesia.

\section{KEYWORDS}

Ropivacaine, Fentanyl, Epidural Anaesthesia, Sensory Block, Motor Block.

HOW TO CITE THIS ARTICLE: Rao AM, Prasad AH, Babu VK. Epidural fentanyl speeds the onset of sensory and motor blocks during epidural ropivacaine anaesthesia. J. Evolution Med. Dent. Sci. 2016;5(58):4002-4005, DOI: 10.14260/jemds/2016/916

\section{INTRODUCTION}

Recent trends suggests that regional anaesthesia is replacing general anaesthesia in all most all the surgeries below umbilicus mainly because its benefits such as avoidance of polypharmacy, airway manipulation, misplacement of endotracheal tube, hypo or hyperventilation, vomiting, pulmonary aspiration.(1) The delayed onset time of sensory

Financial or Other, Competing Interest: None.

Submission 12-06-2016, Peer Review 07-07-2016,

Acceptance 13-07-2016, Published 20-07-2016.

Corresponding Author:

Dr. Vankineni Kuchela Babu,

Chief Consultant and HOD,

Department of Anaesthesiology and Critical Care,

Seven Hills Hospital,

Visakhapatnam.

E-mail: kuchelababu@yahoo.com

DOI: $10.14260 /$ jemds $/ 2016 / 916$ block in epidural anaesthesia is sometimes a drawback for clinical practice. Shortening the onset time of sensory block is a practical goal to improve the quality of epidural anaesthesia. A variety of adjuvants are used for epidural infusion to enhance analgesia while minimizing side effects, like clonidine.(2,3) epinephrine.(4,5) ketamine.(6) sodium bicarbonate.(7) etc. The addition of fentanyl to a local anaesthetic solution is widely used during epidural anaesthesia.(8) The addition of fentanyl to lidocaine.(8) bupivacaine.(9) and mepivacaine.(10) solutions produces a rapid onset of sensory block during epidural anaesthesia. Conversely, other investigators have reported no change in the onset of analgesia with the addition of fentanyl to epidural mepivacaine.(11) Alkalinisation of local anaesthetic solution has been used to shorten the onset time.(12) Ropivacaine, a long-acting amino-amide type local anaesthetic is widely used in epidural anaesthesia. 


\section{AIMS AND OBJECTIVES}

The aim of this prospective randomised study is to examine the effect of epidural fentanyl on the onset times of sensory and motor blocks during epidural ropivacaine anaesthesia.

\section{MATERIALS AND METHODS}

After obtaining informed consent and permission from hospital scientific and ethical committee, 40 patients with ASA grade I and II randomly allocated into two groups: Epidural Fentanyl (EF) and Intravenous Fentanyl (IF) with 20 patients in each group who are admitted into the Seven Hills Hospital, Visakhapatnam for undergoing lower extremity orthopaedic, urologic, gynaecological, and lower abdominal surgeries are included in this study.

Randomisation is done using computer-based software into two different groups.(13) Patients with bleeding disorders, infections at puncture site, history of opioid dependence, allergic to study drugs, pregnant ladies, age $<18$ years, and morbidly obese patients are excluded from this study.

Patients are monitored with electrocardiogram, noninvasive arterial blood pressure, heart rate, and pulse oximetry during surgery.

With patients in sitting position, the epidural space is identified with an 18-Gauge Tuohy's needle by the loss of resistance technique.(14) A test dose of $3 \mathrm{~mL}$ of solution containing $3 \mathrm{~mL}$ of $2 \%$ lignocaine with $15 \mu \mathrm{g}$ of adrenaline in $1: 2,00,000$ dilutions is given for identification of intravascular or intrathecal placement of epidural needle.(15)

After the test dose, Epidural Fentanyl (EF) group receive $20 \mathrm{~mL}$ of $0.75 \%$ ropivacaine plus $100 \mu \mathrm{g}$ of fentanyl $(2 \mathrm{~mL})$ followed by IV injection of $2 \mathrm{~mL}$ of normal saline. The patient in the Intravenous Fentanyl (IF) group receive $20 \mathrm{~mL}$ of $0.75 \%$ ropivacaine plus $2 \mathrm{~mL}$ of normal saline followed by IV injection of $100 \mu \mathrm{g}$ fentanyl $(2 \mathrm{~mL})$.

The sensory block is assessed by pinprick method in left anterior axillary line at 2 minutes interval for 20 mins. Onset of sensory block is defined as time from epidural injection to the occurrence of sensory block at $\mathrm{T}_{10}$ dermatome. The upper level of sensory block is recorded.

The motor block is assessed at 2 minutes interval for 40 mins by modified Bromage scale, $(4=$ no movement, $3=$ unable to raise extended leg or bend knee, $2=$ unable to raise the extended leg, but able to bend the knee, $1=$ able to move feet, but not able to bend the knees, $0=$ complete leg and foot movement).(16) The onset of motor block is defined as the time from epidural injection to occurrence of motor block at each scale.

Hypotension (Systolic blood pressure $<100 \mathrm{mmHg}$ or a decrease of more than $30 \%$ from baseline) is treated with IV ephedrine as needed. Side effects such as nausea, vomiting, pruritus, respiratory depression, or shivering are recorded during surgery.

Based on a previous study.(17), an estimated standard deviation of 5 min for the onset of sensory block during epidural ropivacaine anaesthesia is used. A decrease in the onset time of $30 \%$ is considered clinically significant. On the basis of these estimates, a sample size of 20 patients in each group is sufficient to get a two-tailed type I error of 0.05 and

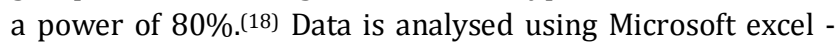
2007 and computer-based software programme under the name of SPSS statistics version - 20 marketed by IBM corporation 2011.

\section{RESULTS AND DISCUSSION}

The two study groups are similar in demographic profile (Age, sex, height, weight) assessed with independent samples t-test and independent samples Kruskal-Wallis test as shown in table-1. The anaesthetic characters are shown in table- 2 and analysed with independent samples t-test. The incidence of different complication was analysed by one-way ANOVA test. Microsoft office excel - 2007 and computer-based software programme under the name of SPSS statistics version 20 marketed by IBM Corporation 2011 are used for statistical analysis.

In this randomised non-blinded study, effect of epidural fentanyl and intravenous fentanyl on onset time of sensory and motor block of epidural ropivacaine anaesthesia is analysed.

In this study, the demographic profile (Age, sex, height, and weight) between the two groups is analysed with independent sample t-test and hypothesis is tested with independent samples Kruskal-Wallis test. The p-value is $>0.05$ indicating insignificant differences among the anthropometric variables among the groups. Similar results among the anthropometric variables is found by Tomar GS et al(19) while comparing two different doses of fentanyl added to bupivacaine for intermittent epidural labour analgesia. They analysed demographic data using ANOVA test and found a p-value of $>0.05$ concluding there is no significant difference in the study groups.

In this study, the mean sensory block onset time $\left(\mathrm{T}_{10}\right.$ dermatome) of epidural fentanyl group is found to be $10.90 \pm 2.81$ (mean \pm SD) minutes and that of intravenous fentanyl group is $16 \pm 3.03$ (mean \pm SD) minutes. Data is analysed using independent samples t-test with a t-value of 5.525 and $\mathrm{p}$-value of 0.000 (p-value <0.05), which is statistically significant. Similar results are obtained by Cherng $\mathrm{CH}$ et al(8) while comparing the sensory block onset time $\left(\mathrm{T}_{10}\right.$ dermatome) with (EF group) epidural administration of 17 $\mathrm{mL}$ of $2 \%$ lidocaine plus $100 \mu \mathrm{g}$ fentanyl and followed by intravenous (IV) injection of $2 \mathrm{~mL}$ of normal saline, (IF group) epidural administration of $17 \mathrm{~mL}$ of $2 \%$ lidocaine plus $2 \mathrm{~mL}$ of normal saline and followed by IV injection of $100 \mu \mathrm{g}$ of fentanyl, and (C group) epidural administration of $17 \mathrm{~mL}$ of $2 \%$ lidocaine plus $2 \mathrm{~mL}$ of normal saline and followed by IV injection of $2 \mathrm{~mL}$ of normal saline. They found the onset time of sensory block up to $\mathrm{T}_{10}$ dermatome was significantly more rapid in the EF group (8.3+/-3.7 minutes) than that of the IF group $(13.1+/-4.2$ minutes, $\mathrm{P}<.05)$ or $\mathrm{C}$ group $(14.2+/-5.4$ minutes, $\mathrm{P}<.05$ ).

In this study, the mean motor block onset time for modified Bromage scale 1 and 2 of epidural fentanyl group is found to be $14.95 \pm 5.43$ (mean \pm SD) minutes and that of intravenous fentanyl group is found to be $26.40 \pm 5.94$ (mean \pm SD) minutes. Analysis of data with independent samples t-test give the resultant $t$-value of -6.360 and a p-value of 0.000 ( $p$-value $<0.05$ ), which is statistically significant. ChenHwan Cherng et al(20) examined the onset times of sensory and motor block during epidural ropivacaine anaesthesia with and without the addition of fentanyl to the epidural solution. They found that the onset times of motor block up to Bromage scale 1 and 2 were significantly more rapid in the EF group (11.9 \pm 4.6 and $24.4 \pm 5.9 \mathrm{~min})$ than in the IF group (16.9 \pm 4.7 and $30.8 \pm 5.6 \mathrm{~min}, \mathrm{P}<0.05)$ or $\mathrm{C}$ group $(18.3 \pm 4.9$ and $32.7 \pm 5.7 \mathrm{~min}, \mathrm{P}<0.05)$. They concluded that onset time of 
motor block to the modified Bromage scores 1 and 2 was significantly more rapid in the EF group compared with the IF and $\mathrm{C}$ groups.

In this study, the upper sensory level is up to T4 dermatome level in both the groups, which is analysed using ANOVA test with $F$ value of 0.060 and p-value of 0.809 showing statistical insignificance. Similar statistical insignificance in upper sensory level is found in the study of Chen-Hwan Cherng et al(20) They analysed data using the Kruskal-Wallis test and the Dunn's multiple comparison procedure for post hoc comparison and found a p-value $>0.05$.

In this study, incidence of complication like shivering, hypotension, pruritus, nausea, vomiting, respiratory depressions, urinary retention are recorded. There is no incidence of pruritus, nausea and vomiting, respiratory depression, which are more common with fentanyl. Incidence of hypotension and shivering are noted in both groups. Incidence of complications in both epidural fentanyl and intravenous fentanyl group analysed with one-way ANOVA test, which gave a p-value $>0.05(0.135)$ showing statistical insignificance. Similar results are found by Cherng $\mathrm{CH}$ et al(8) Tomar GS et al(19) Chen-Hwan Cherng et al(20) with p-value $>0.05$ showing statistical insignificance.

\begin{tabular}{|c|c|c|c|}
\hline Data & $\begin{array}{c}\text { Epidural } \\
\text { Fentanyl (EF) }\end{array}$ & $\begin{array}{c}\text { Intravenous } \\
\text { Fentanyl } \\
\text { (IF) }\end{array}$ & $\begin{array}{c}\text { Significance } \\
\text { (2 - tailed) }\end{array}$ \\
\hline $\begin{array}{c}\text { Age } \\
\text { (Yrs. })\end{array}$ & $37.95 \pm 8.62$ & $42.2 \pm 12.98$ & 0.23 \\
\hline $\begin{array}{c}\text { Height } \\
\text { (Cm) }\end{array}$ & $162.8 \pm 8.82$ & $164.55 \pm 9.37$ & 0.55 \\
\hline $\begin{array}{c}\text { Weight } \\
\text { (Kg) }\end{array}$ & $65.55 \pm 11.90$ & $61.05 \pm 11.63$ & 0.23 \\
\hline $\begin{array}{c}\text { Sex } \\
\text { (M:F) }\end{array}$ & $11: 9$ & $11: 9$ & 1.00 \\
\hline \multicolumn{4}{|c|}{ Table 1: Demographic Profile } \\
\hline
\end{tabular}

Table-1: Demographic profile among the groups. There is no statistical significance among the groups as $p$-value $>0.05$. Values expressed in Mean \pm SD.

\begin{tabular}{|c|c|c|c|}
\hline Variables & $\begin{array}{c}\text { Epidural } \\
\text { Fentanyl }\end{array}$ & $\begin{array}{c}\text { Intravenous } \\
\text { Fentanyl }\end{array}$ & $\begin{array}{c}\text { Significance } \\
\text { (2-tailed) }\end{array}$ \\
\hline $\begin{array}{c}\text { Onset of } \\
\text { Motor Block } \\
\text { In Minutes }\end{array}$ & $14.95 \pm 5.43$ & $26.40 \pm 5.94$ & 0.000 \\
\hline $\begin{array}{c}\text { Onset of } \\
\text { Sensory } \\
\text { Block In } \\
\text { Minutes }\end{array}$ & $10.90 \pm 2.81$ & $16 \pm 3.03$ & 0.000 \\
\hline $\begin{array}{c}\text { Upper Level } \\
\text { of Sensory } \\
\text { Block }\end{array}$ & $1.70 \pm 0.571$ & $1.75 \pm 0.716$ & 0.809 \\
\hline \multicolumn{3}{|c|}{ Table 2: Anaesthetic Characters } \\
\hline
\end{tabular}

Table-2: Comparisons of anaesthetic characters among the groups. There is a statistical significance among the groups as $p$-value $<0.05$. Values expressed in Mean $\pm S D$.

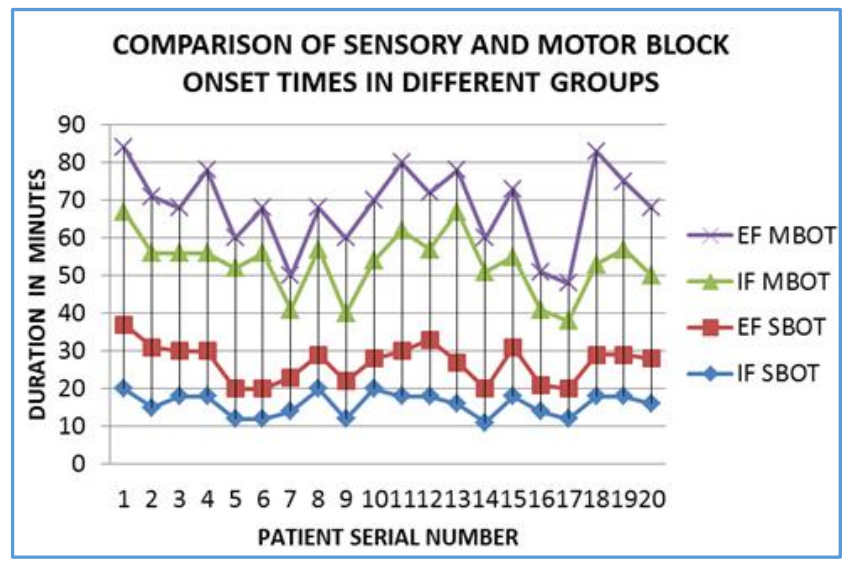

Fig. 1: Comparison of Sensory and Motor Block Onset Times among different groups. EF-Epidural Fentanyl, IFIntravenous Fentanyl, SBOT-Sensory Block Onset Time, MBOT-Motor Block Onset Time

\section{CONCLUSION}

From this study, it was concluded that epidural administration of the mixture of $100 \mu \mathrm{g}$ fentanyl and $0.75 \%$ ropivacaine solution accelerated the onset of sensory and motor blocks during epidural ropivacaine anaesthesia without significant fentanyl related side effects. Fentanyl is a useful adjunct to local anaesthetic ropivacaine for epidural anaesthesia.

\section{ACKNOWLEDGEMENT}

This research was supported by Seven Hills Hospital and Healthcare Ltd., Dr. Sanjay J Ahullwalia, Dr. K Srinivas, Dr P Narsinga Rao, Dr. V Ganesh, Dr. Nomesh, Dr. Neeta, Dr. Amit Saple, Dr. Anjali Saple, Dr. Archana Mahato, Dr. Kalikumari, Dr. Alok Mazzumdar, Dr. Susanta Mallik, Dr. J. M Shah, Dr. B B Das. We are thankful to our colleagues Dr. Sandhya Nair, Dr. Sushree Rath, Dr. Kinjal R Shah, Dr. V. Padmavati, Dr. Krisna Kishore, Dr. S. Kiran, Dr. Swetabindu, and Dr. Soujanya who provided expertise that greatly assisted the research, although they may not agree with all of the interpretations provided in this paper.

We are also grateful to B Chandrasekhar, V Kondalrao, Srinivas, and Sridhar for assistance with anaesthetic technique, and Dr. Preeti Pallavi who moderated this paper and in that line improved the manuscript significantly.

We have to express our appreciation to the Dr V Kuchela Babu for sharing their pearls of wisdom with us during the course of this research. We are also immensely grateful to $\mathrm{Dr}$ K Srinivas, and Dr Sanjay J Ahullwalia for their comments on an earlier versions of the manuscript, although any errors are our own and should not tarnish the reputations of these esteemed professionals.

\section{REFERENCES}

1. Karia SP, Patel C, Arora S, et al. To study the efficacy of ropivacaine $(0.75 \%)$ with or without butorphanol as an adjuvant in single shot epidural anaesthesia in lower limb orthopaedic surgeries. IJBR 2014;5(12):725-30.

2. Paech MJ, Pavy TJ, Orlikowski CE, et al. Postoperative epidural infusion: a randomised, double-blind, dosefinding trial of clonidine in combination with bupivacaine and fentanyl. Anaesth Analg 1997;84(6):1323-8. 
3. Niemi G, Breivik H. Adrenaline markedly improves thoracic epidural analgesia produced by a low-dose infusion of bupivacaine, fentanyl, and adrenaline after major surgery: a randomised, double-blind, cross-over study with and without adrenaline. Acta Anaesthesiol Scand 1998;42(8):897-909.

4. Sakaguchi Y, Sakura S, Shinzawa M, et al. Does adrenaline improve epidural bupivacaine and fentanyl analgesia after abdominal surgery? Anaesth Intensive Care 2000;28(5):522-6.

5. Lauretti GR, Gomes JM, Reis MP, et al. Low doses of epidural ketamine or neostigmine, but not midazolam, improved morphine analgesia in epidural terminal cancer pain therapy. J Clin Anaesth 1999;11(8):663-8.

6. Nickells JS, Vaughan DJ, Lillywhite NK, et al. Speed of onset of regional analgesia in labour: a comparison of the epidural and spinal routes. Anaesthesia 2000;55(1): 17-20.

7. Arcioni R, Palmisani S, Tigano S, et al. Combined intrathecal and epidural magnesium sulfate supplementation of spinal anaesthesia to reduce postoperative analgesic requirements: a prospective, randomised, double-blind, controlled trial in patients undergoing major orthopaedic surgery. Acta Anaesthesiol Scand 2007;51(4):482-9.

8. Cherng $\mathrm{CH}$, Wong CS, Ho ST. Epidural fentanyl speeds the onset of sensory block during epidural lidocaine anaesthesia. Reg Anaesth Pain Med 2001;26(6):523-6.

9. Johnson C, Ransil BJ, Oriol N. Comparison of onset time between $0.5 \%$ bupivacaine and 3\% 2-chloroprocaine with and without $75 \mu \mathrm{g}$ fentanyl. Reg Anaesth 1991;16(4): 228-31.

10. Kasaba T, Yoshikawa G, Seguchi T, et al. Epidural fentanyl improves the onset and spread of epidural mepivacaine analgesia. Can J Anaesth 1996;43(12):1211-5.
11. Boidin MP, Sulimma H, Hamers SE. Fentanyl in $2 \%$ mepivacaine compared with fentanyl in $0.5 \%$ bupivacaine: two parallel controlled double-blind studies. Acta Anaesthesiol Belgica 1991;42(2):93-9.

12. Wong K, Strichartz GR, Raymond SA. On the mechanisms of potentiation of local anaesthetics by bicarbonate buffer: drug structure-activity studies on isolated peripheral nerve. Anaesth Analg 1993;76(1):131-43.

13. Urbaniak GC, Plous S. Research Randomizer Retrieved on June 22, 2013, http://www.randomizer.org/

14. Beilin Y, Arnold I, Telfeyan C, et al. Quality of analgesia when air versus saline is used for identification of the epidural space in the parturient. Reg Anaesth Pain Med 2000;25(6):596-9.

15. Moore DC, Batra MS. The components of an effective test dose prior to epidural block. Anaesthesiology 1981;55(6): 693-6.

16. Merson N. A comparison of motor block between ropivacaine and bupivacaine for continuous labour epidural analgesia. AANA J 2001;69(1):54-8.

17. Gautier P, De Kock M, Steenberge AV. A double-blind comparison of $0.125 \%$ ropivacaine with sufentanil and $0.125 \%$ bupivacaine with sufentanil for epidural labour analgesia. Anaesthesiology 1999;90(3):772-8.

18. Bourke GJ, Daly LE, McGilvray J. Interpretation and uses of medical statistics. 3rd edn. Oxford Blackwell Scientific Publications 1985:312-4.

19. Tomar GS, Tiwari A, Godwin RB, et al. A comparative study of two different doses of fentanyl added to bupivacaine for intermittent epidural labour analgesia: a prospective randomised double blind study. J Anaesthe Clinic Res 2011;5(2):147.

20. Cherng CH, Yang CP, Wong CS. Epidural fentanyl speeds the onset of sensory and motor blocks during epidural ropivacaine anaesthesia. Anaesth Analg 2005;101(6): 1834-7. 